\title{
THE EFFECT OF ORAL CONTRACEPTIVE ON BREAST CANCER: A META-ANALYSIS
}

\author{
Dilma'aarij'), Setyo Sri Rahardjo²), Eti Poncorini Pamungkasari²) \\ 1)Masters Program in Public Health, Universitas Sebelas Maret \\ 2)Faculty of Medicine, Universitas Sebelas Maret
}

\begin{abstract}
Background: Oral contraceptive is the most commonly prescribed contraceptive in women of reproductive age. Estrogen, as a component of oral contraceptives, has been postulated induce the risk of breast cancer. The purpose of this study was to assessed the effect of oral contraceptive on breast cancer using meta-analysis.

Subjects and Method: A systematic review and meta analysis study was conducted by following PRISMA flow diagram. The study collected articles from PubMed, Science Direct, and Google Scholar databases. Keywords used "Women aged 15-80 Years" OR "Women of Menopause" AND "Contraceptive Pills" AND "Breast Cancer". The inclusion criteria were full text observational studies, published from 2010 to 2020 , used English language, and reported adjusted Odds Ratio. The articles that met the criteria were assessed using RevMan 5.3 application program.

Results: 10 case control studies were analyzed for meta analysis. This study found that oral contraceptive had possibility to breast cancer 1.48 times than non hormonal contraceptive $(\mathrm{aOR}=1.48 ; 95 \% \mathrm{CI}=1.16$ to $1.90 ; \mathrm{p}=0.002)$.

Conclusion: Oral contraceptive increases the risk of breast cancer 1.48 times than non hormonal contraceptive.
\end{abstract}

Keywords: oral contraceptive, breast cancer

\section{Correspondence:}

Dilma'aarij RiskiAgustia. Masters Program in Public Health, Universitas Sebelas Maret. Jl. Ir. Sutami 36A, Surakarta 57126, Central Java. Email: dilmarij@gmail.com. Mobile: 082230100871. 